\title{
Morphological features in a neutral lipid storage disease
}

\author{
GERARD SLAVIN, E. J. WILLS, JOAN E. RICHMOND, I. CHANARIN, T. ANDREWS, \\ AND GREGORY STEWART
}

From the Northwick Park Hospital and Clinical Research Centre, Harrow, Middx

SYNOPSIS The morphological changes in a patient with a generalized storage disease characterized by the intracellular deposition of neutral lipid are described. There is widespread accumulation of lipid in the cytoplasm of many cells and in occasional nuclei. Diagnosis may be facilitated by the recognition of clear vacuoles in the cytoplasm of granulocytes in blood films. In jejunal biopsies vacuolation of the epithelial cells may simulate the appearances of a-betalipoproteinaemia.

The lipid inclusions consist largely of normal triglycerides and are free in the cytoplasm, unassociated with any organelle. The biochemical basis of the lesions is uncertain. Although there are lipoprotein abnormalities the primary defect appears to be intrinsic to the cell and may involve either a defective cytoplasmic lipase or an impaired uptake and utilization of fatty acids by mitochondria.

Lipid storage diseases characterized by deposition of neutral lipids in the tissues are rare. Such lesions may contain cholesterol and its esters, triglycerides or mixtures of both. Wolman's disease and cholesteryl ester storage disease are characterized by the widespread deposition of neutral cholesteryl esters. In Wolman's disease there may be in addition an excess of triglycerides. More localized deposits of neutral lipid have been described in a number of reports: myopathies may be associated with abnormal lipid accumulation in muscle fibres (Bradley $e t$ al, 1972; Engel et al, 1970; Engel and Siekert, 1972). Jordans (1953) described two brothers with progressive muscular dystrophy whose leucocytes and monocytes contained large neutral lipid vacuoles. A similar anomaly of white cells was subsequently described in two sisters with ichthyosis but without myopathy (Rosenazajn et al, 1966).

This report describes the morphological features in a patient who showed lipid vacuolation of white cells, ichthyosis, and myopathic changes in association with a generalized neutral lipid storage. The clinical aspects of this patient have been described elsewhere (Chanarin et al, 1975).

\section{Case Report}

Miss G.D., a Ugandan Asian immigrant aged 22 years, presented with an itchy skin lesion which had been present since birth. She complained also of menorrhagia but had no other symptoms and coped satisfactorily with heavy work in a laundry. Her diet was largely vegetarian but supplemented by some daily milk and occasional eggs. Her parents were not consanguineous. There was no family history of death in infancy or neonatal period. Examination showed a plump, healthy girl of normal intelligence with an ichthyosiform rash most marked on the limbs and abdomen. No other abnormality was found. There was no evidence of retinitis pigmentosa. The tonsils were not enlarged and were of normal colour.

The blood count showed an iron deficiency (Hb 8.2 g/dl) which responded fully to oral ferrous sulphate therapy. The blood film showed hypochromia of red cells; acanthocytes were not present. Multiple vacuoles were seen in the cytoplasm of neutrophil (fig 1), eosinophil, and basophil polymorphs and in monocytes but not in lymphocytes or red cells. They were of $1-2 \mu \mathrm{m}$ in diameter and took up fat stains such as oil red $O$. Unlike sequestrene changes they were present in cells of blood films prepared from fresh blood samples as well as in motile leucocytes in wet preparations. Nuclear changes characteristic of a sequestrene effect were not seen.

CLINICAL INVESTIGATIONS

A chest radiograph and electrocardiogram were 


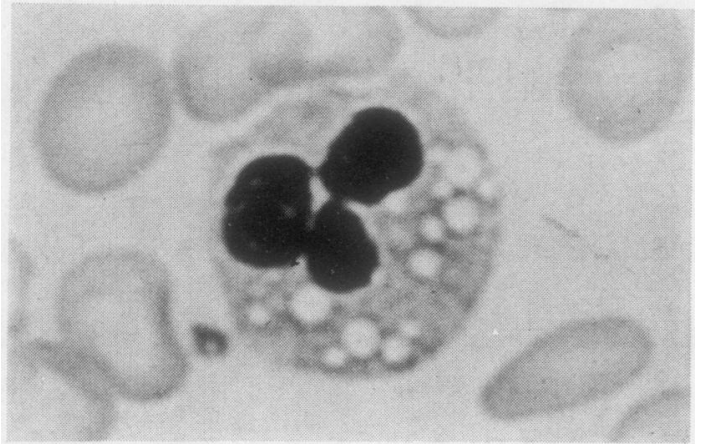

Fig 1 Granulocyte in peripheral blood showing cytoplasmic lipid vacuoles. (May-Grünwald-Giemsa $\times 2500)$

normal. An electroencephalogram showed minor changes in frontotemporal and temporoparietal areas suggesting diffuse cortical abnormality. Electromyography revealed, on voluntary contraction, a pattern of small markedly polyphasic units consistent with a neuromyopathy.

Explanation of the possible widespread nature of the disorder was made to the patient, and her consent to further investigation was obtained.

\section{Material and Methods}

\section{LIGHT MICROSCOPY}

Tissues were obtained by biopsy from bone marrow, jejunum, stomach, rectum, liver, endometrium, vastus lateralis muscle, and skin. All tissues were paraffin embedded, and, in addition, with the exception of the jejunal biopsy, cryostat sections were examined by standard procedures for the histochemical analysis of lipid (Chayen et al, 1969). Muscle fibres were typed using the ATPase reaction (Padykula and Herman, 1955).

\section{ELECTRON MICROSCOPY}

Peripheral blood buffy coat specimens prepared by the method of Anderson (1965), small bone marrow fragments, $0 \cdot 5-1 \mathrm{~mm}^{3}$ blocks from stomach, rectum, skin, and liver biopsy specimens, and monolayers of cultured skin fibroblasts were fixed in chilled cacodylate buffered $2.5 \%$ glutaraldehyde (Sabatini $e t$ al, 1963), washed in sucrose-cacodylate solution, and postfixed in $1 \%$ osmium tetroxide in phosphate buffer (Millonig, 1961). Duplicate buffy coat and bone marrow samples were also fixed by the combined glutaraldehyde-osmium tetroxide technique of Hirsch and Fedorko (1968). All specimens were dehydrated in a graded series of ethanol solutions and embedded in Epikote 812, essentially as des- cribed by Luft (1961). One $\mu \mathrm{m}$ sections were stained with $1 \%$ toluidine blue in $1 \%$ aqueous borax solution for light microscopy. Ultrathin sections for electron microscopy were contrast stained with alcoholic uranyl acetate (Watson, 1958) followed by lead citrate (Reynolds, 1963).

\section{Results}

\section{LIGHT MICROSCOPY}

In the sternal marrow lipid vacuoles were present in the granulocyte series, in monocytes but not in erythroblasts or megakaryocytes. Vacuoles were absent from lymphoblasts, relatively small and often solitary in promyelocytes, but more prominent in myelocytes and particularly so in metamyelocytes.

The jejunal mucosa showed a striking vacuolation of the columnar epithelial cells beginning about one-sixth of the way up the villus and increasing until maximal in cells at the tip (figs 2 and 3 ). Within an individual cell multiple vacuoles were dispersed throughout the cytoplasm. Paneth cells and goblet cells contained only sparse small vacuoles. In the lamina propria, scanty foamy macrophages were found.

Lipid deposition was present in the glandulat cells from the body of the stomach (fig 4) but wa lacking in the mucus-secreting cells of the surfas epithelium and gastric pits. Similar vacuolation of epithelial cells was found in the rectal mucosa, most marked in subnuclear distribution (fig 5). Foamy macrophages and vacuolated plasma cells were prominent in the lamina propria (fig 5). Free lipid in the lamina propria was particularly well marked.

Liver parenchymal cells showed a fine fatty vacuolation together with larger fat cysts. Foamy macrophages were seen in the sinusoids, and Kupffer cells were enlarged and contained lipid droplets (fig 6). There was mild portal fibrosis with the formation of short spurs but no evidence of cirrhosis.

Endometrial curettings were of early secretory pattern but with heavy lipid deposition in the stromal cells.

Prominent lipid droplets were seen in the vastus $\rightarrow$ lateralis muscle (fig 7) in both fibre types but were more prominent in type I fibres. There was a type I N fibre predominance and type II fibre atrophy.

The skin biopsy showed an ichthyosiform reaction $\stackrel{N}{\circ}$ which did not conform to any of the classical forms $\omega$ of ichthyosis. There was hyperkeratosis with focal 2 parakeratosis and spongiosis. In the upper dermis $\varrho$ there was mild perivascular chronic inflammatory infiltrate. Lipid was present in the keratinizing zone $\stackrel{?}{?}$ but it was not certain whether this was out of $\underline{T}$ proportion to the large excess of keratin. However, $\stackrel{\circ}{\circ}$ there was a marked lipid vacuolation of the cells 


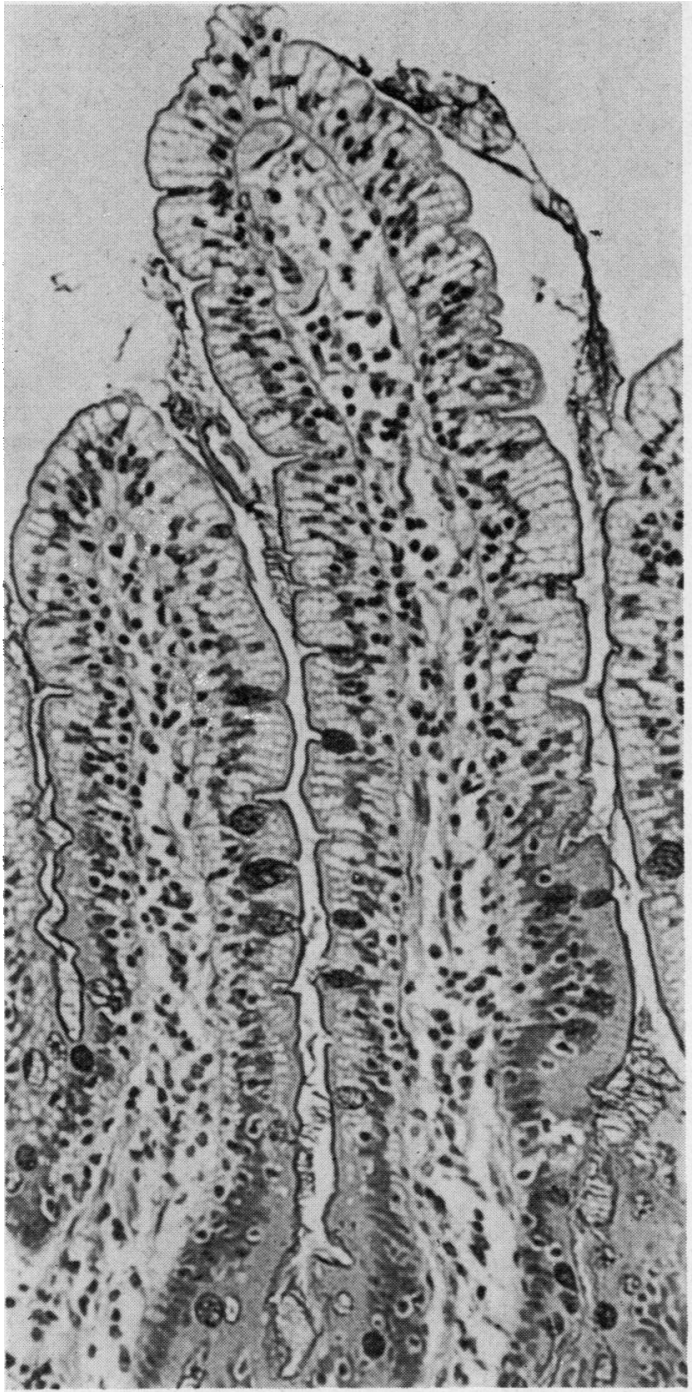

Fig 2

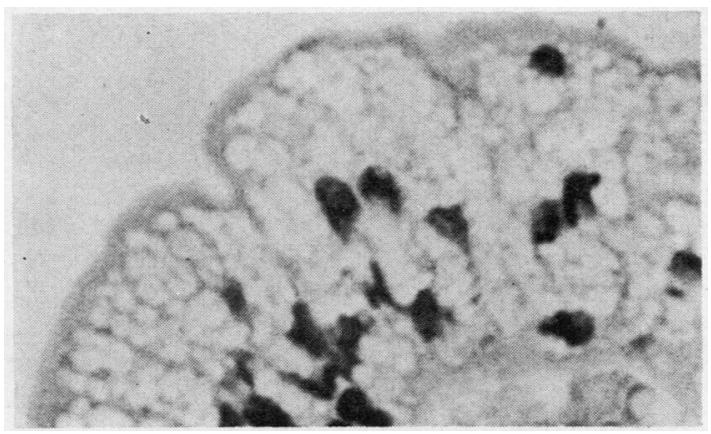

Fig 3

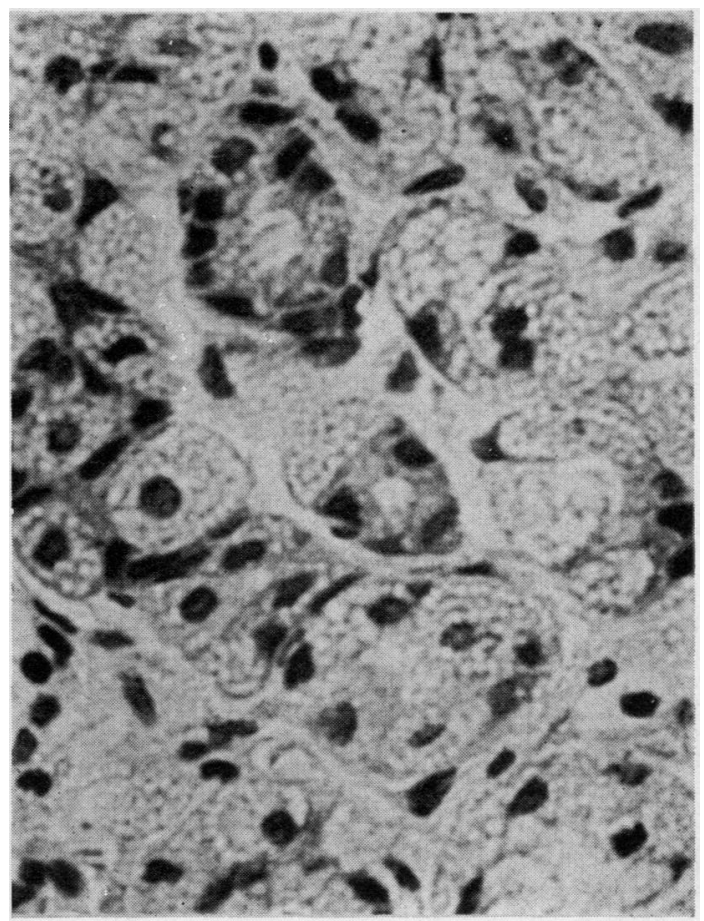

Fig 4

Fig 2 Jejunal villi with vacuolation of columnar epithelial cells increasing in amount towards the tip. (Periodic acid Schiff $\times 280$ )

Fig 3 Detail of epithelial cells at tip of villus showing cytoplasm reduced to a network of vacuoles. (Haematoxylin and eosin $\times 800$ )

Fig 4 Cells of gastric glands distorted by cytoplasmic lipid deposition. ( $H$ and $E \times 680$ ) 


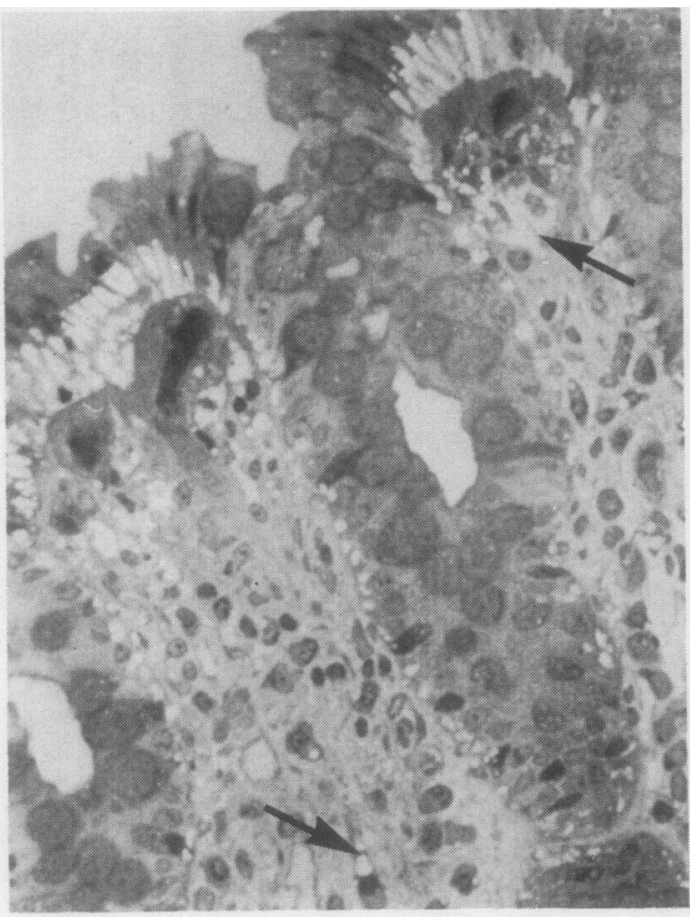

Fig 5

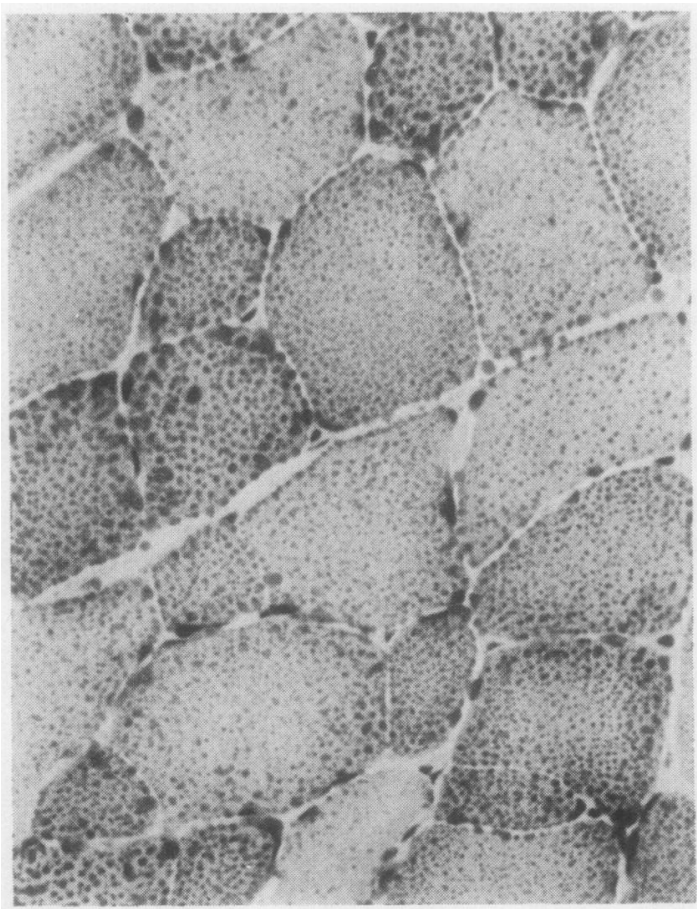

Fig 7

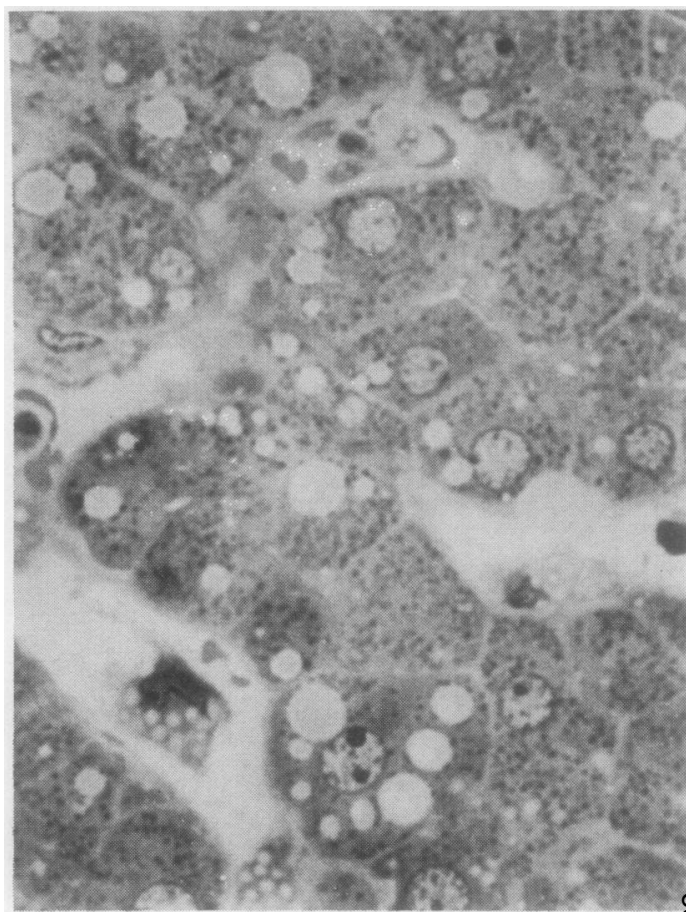

Fig 6

Fig 5 Rectal mucosa with subnuclear lipid deposits maximal in surface epithelium. Note the vacuolation of cells in lamina propria (arrows). (1 $\mu \mathrm{m}$ epoxy section, toluidine blue $\times 360$ )

Fig 6 Liver showing marked lipid accumulation in both parenchymal and sinusoidal cells. (1 $\mu \mathrm{m}$ epoxy section, toluidine blue $\times$ 920)

Fig 7 Striated muscle with an excess of cytoplasmic lipid droplets. (Frozen section, oil red $O \times 280$ )

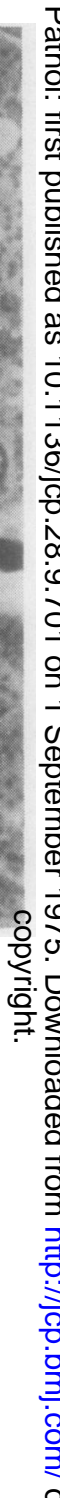

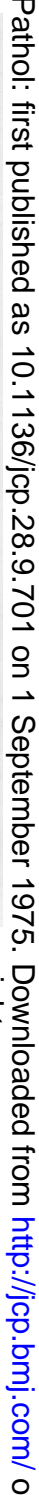

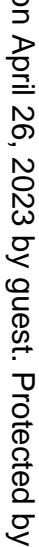


in the stratum basale and also of very minor degree in the prickle cell layers.

\section{LIPID HISTOCHEMISTRY}

The vacuoles had strong oil red $\mathrm{O}$ affinity (fig 7); they were PAS negative but stained red with Nile blue sulphate. Baker's method for phospholipids was negative. Very scanty crystals consistent with cholesteryl esters were present in occasional epithelial vacuoles in liver and rectum when examined by polarized light. These were more prominent in the lamina propria of the rectum. The Schultz test for cholesterol was weakly positive in the rectal mucosa. It was concluded that the lipids present in the tissues were neutral fat, largely triglyceride but with a very minor component of cholesteryl esters.

\section{CHROMOSOME ANALYSIS}

Peripheral blood lymphocytes showed a normal female karyotype with no evidence of mosaicism.

\section{ELECTRON MICROSCOPY}

Electron microscopy confirmed the histological distribution of lipid and showed that it was present in a wide variety of cell types. In peripheral blood and sternal marrow (fig 8), in addition to those cells already listed, lipid droplets were seen in erythroblasts, reticulocytes, and occasional lymphocytes.

Surface epithelial cells of the stomach and rectum contained small to medium sized lipid deposits in the subnuclear region of their cytoplasm. In both tissues there was a progressive increase in the number of droplets per cell from the bottom to the luminal surface of the pits or crypts. Similar lipid droplets were seen in the associated goblet cells and argentaffin cells.

Lipid deposits were observed in cells of all layers of the epidermis but were most prominent in the stratum basale (fig 9). Melanocytes contained small amounts of lipid, in both their cell bodies and cytoplasmic processes (fig 9).

Within the lamina propria of the stomach and rectum and the dermis of the skin lipid was present in many types of connective tissue cells; these included plasma cells, mast cells, macrophages, fibroblasts, Schwann cells of both myelinated and unmyelinated nerves, smooth muscle cells of the muscularis mucosae (fig 10), vascular media and arrector pili, and occasional vascular endothelial cells.

In the liver, in addition to the large number of droplets within the cytoplasm, lipid was also seen in occasional parenchymal cell nuclei. Lipofuscin was increased and many mitochondria contained crystalline inclusions.

Almost all the cultured fibroblasts examined contained large numbers of lipid droplets in their cytoplasm (fig 11), and there were occasional nuclear lipid inclusions.

In all instances the lipid within the cytoplasmic matrix took the form of typical triglyceride droplets without a limiting membrane (fig 12). Lipid was not observed in any of the membrane-bound organelles, nor was there any evidence of endocytic uptake or lysosomal breakdown. In the liver, lipid droplets were sometimes partially surrounded by mitochondria.

\section{BIOCHEMISTRY}

Biochemical abnormalities revealed by clinical studies were described previously (Chanarin et al, 1975) and are summarized in the table. The neutral triglyceride content of peripheral blood granulocytes was two to three times greater than normal with no abnormal fatty acids or excessive accumulation of cholesterol or nonesterified fatty acids (NEFA). There was marked elevation of the B-peptide in low density lipoprotein and reduction of the Apeptide in high density lipoprotein profile determined by nephelometry.

A needle biopsy specimen of abdominal subcutaneous fat showed normal basal rates of lipogenesis and lipolysis in vitro as measured by incorporation of ${ }^{14} \mathrm{C}$-glucose into lipid and release of glycerol respectively. Skin fibroblasts in vitro accumulated lipid progressively with increasing age in culture. Incorporation of palmitate ${ }^{1-14} \mathrm{C}$ into triglyceride and its retention in stored lipid was much greater than normal, but metabolism to ${ }^{14} \mathrm{CO}_{2}$ was only $25 \%$ of the rate observed in normal fibroblasts. Addition of L-carnitine to the culture did not modify these abnormalities, and the plasma level of carnitine was normal.

Serum aspartate transaminase and creatine phosphokinase were elevated but urinalysis was normal and myoglobinuria was not demonstrated. Granulocyte acid lipase activity was normal and total serum bile acids were not significantly elevated.

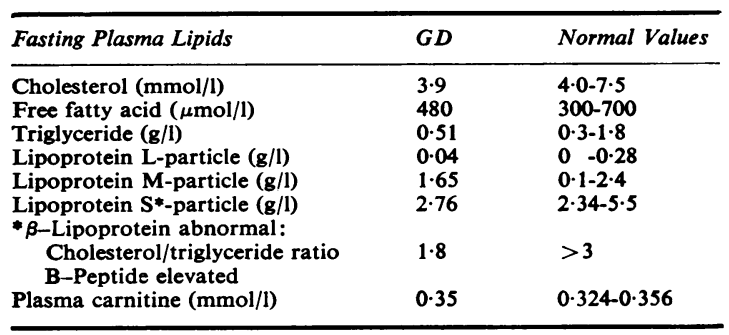

Table Biochemistry: fasting plasma lipid values 


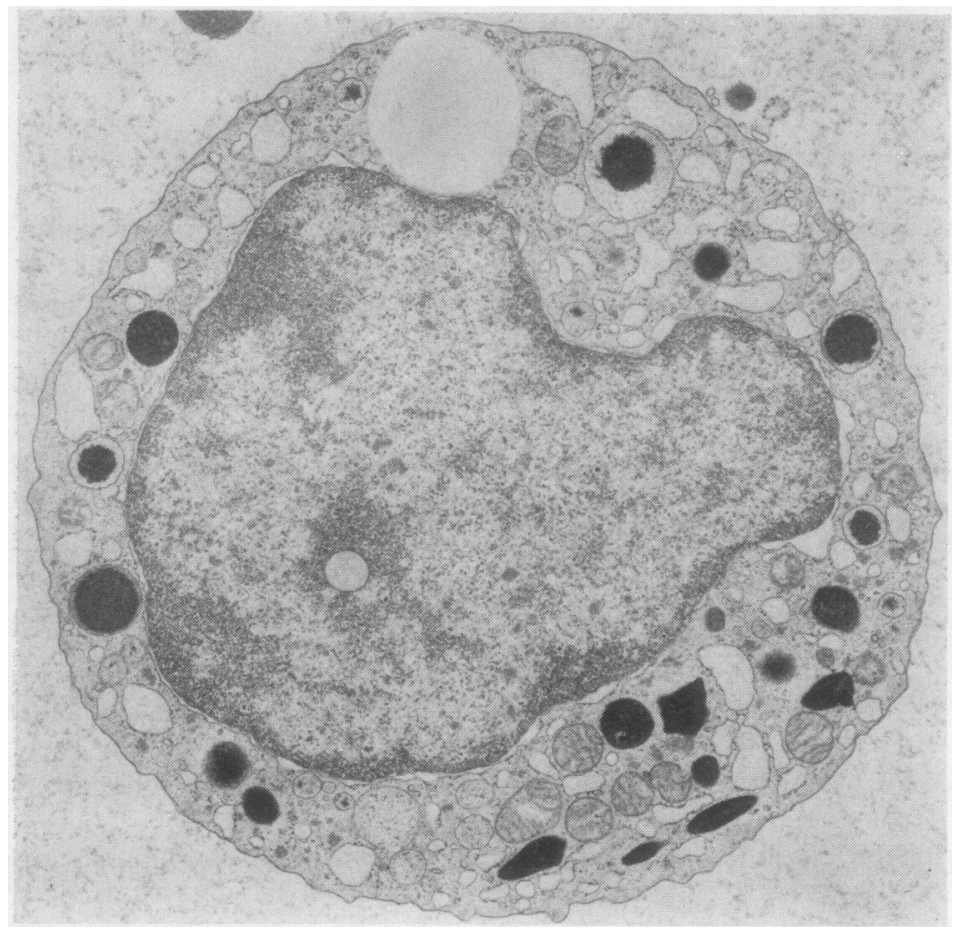

Fig 8 Eosinophil myelocyte containing a single lipid droplet. Bone marrow. $(\times 7500)$

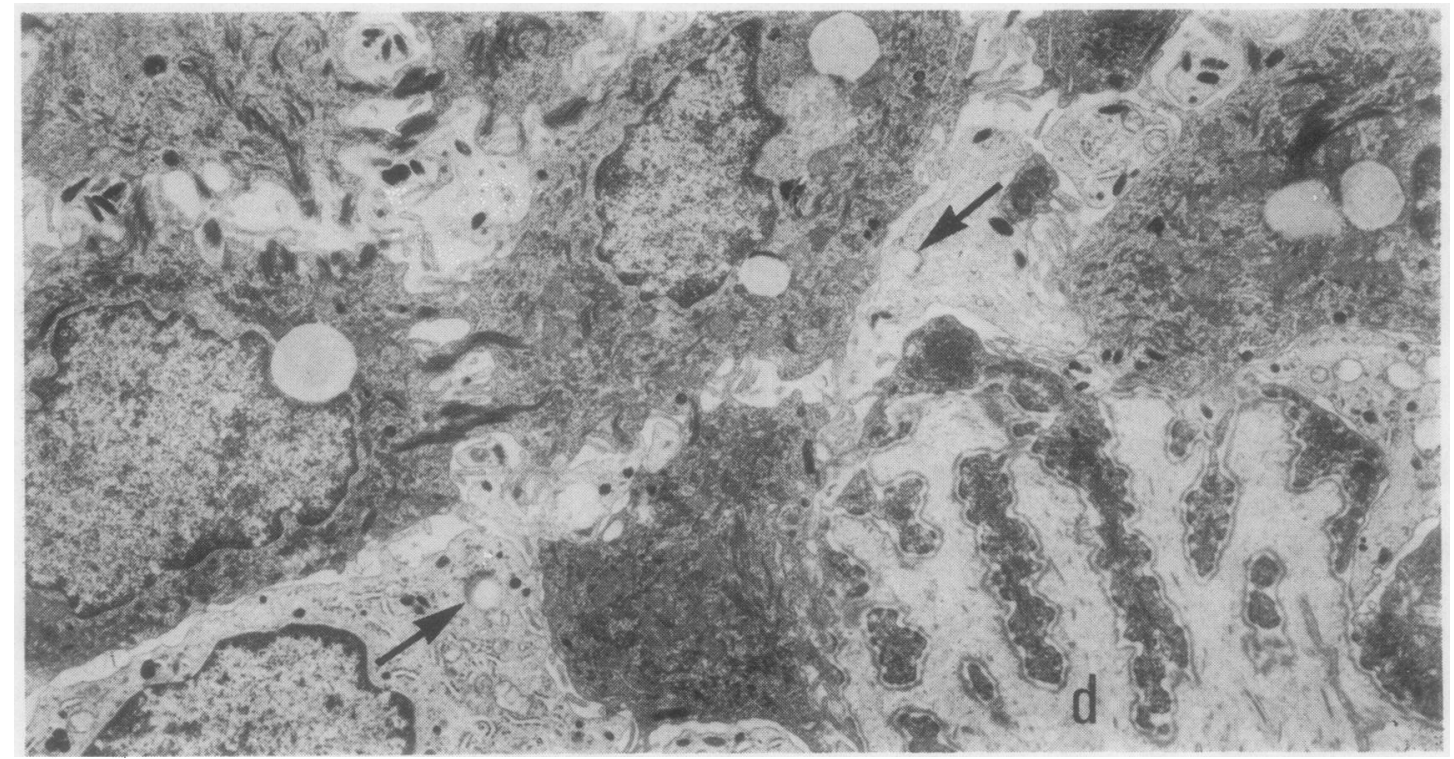

Fig 9 Skin at junction between dermis $(d)$ and epidermis. Lipid is seen in cells of the malpighian layer and in melanocytes (arrows). ( $\times$ 6500) 


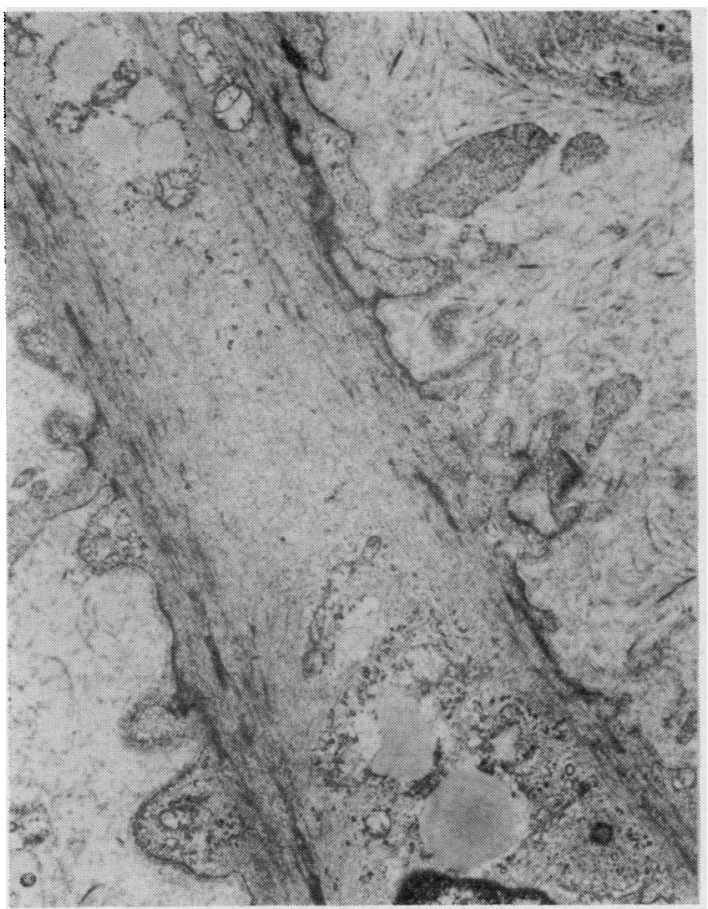

Fig 10

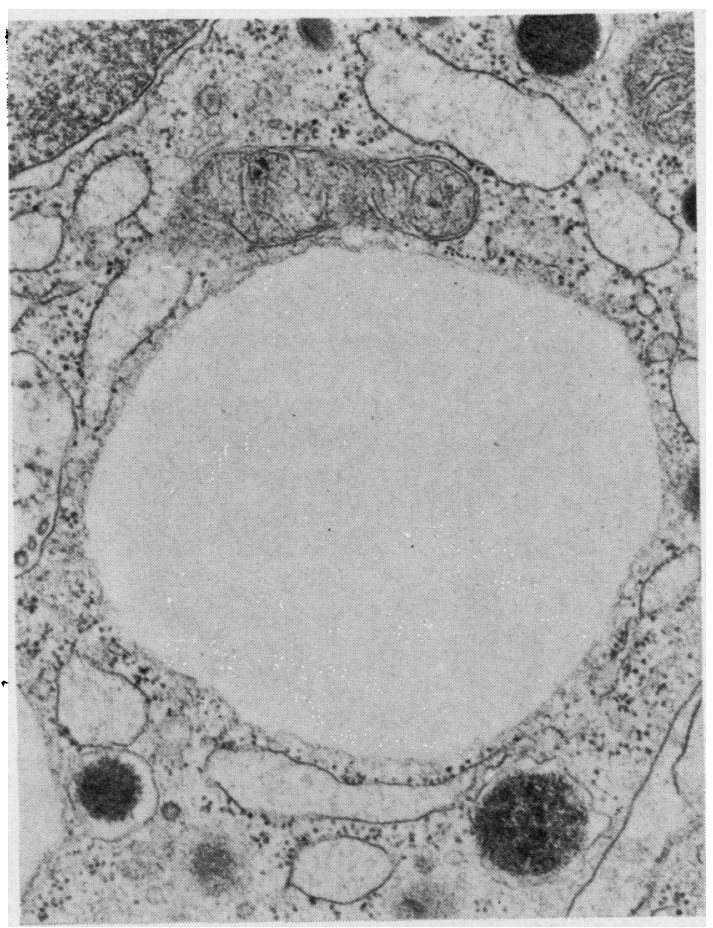

Fig 12

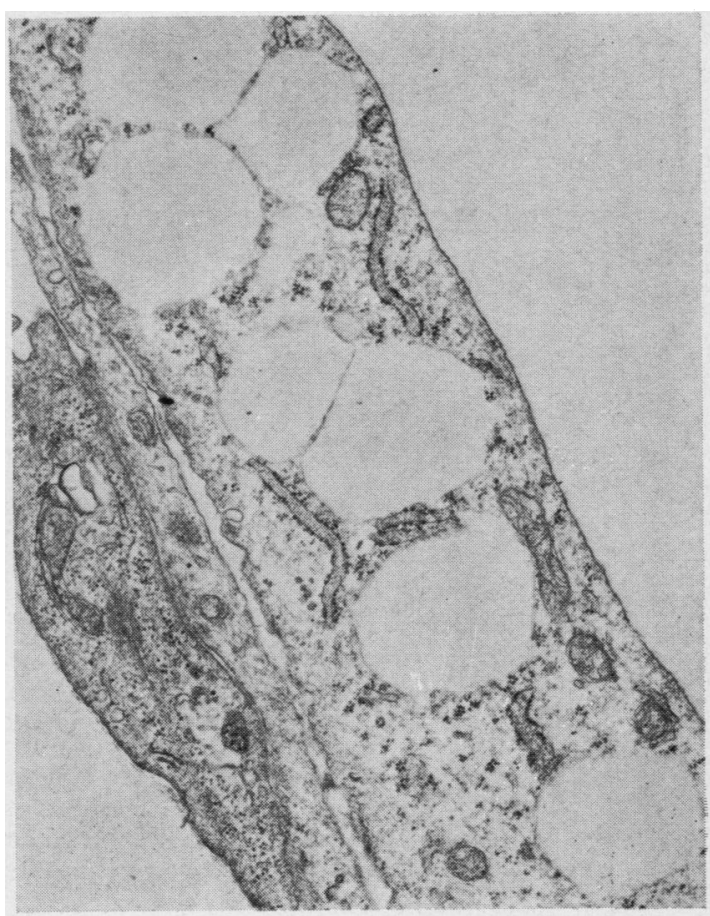

Fig 11

Fig 10 Lipid droplets within a smooth muscle cell of rectal muscularis mucosae. $(\times 8500)$

Fig 11 Portion of a cultured fibroblast containing large amounts of lipid. $(\times 18000)$

Fig 12 Detail of lipid droplet in bone marrow myelocyte. $(\times 40000)$ 
INTRACELLULAR METABOLISM OF TRIGLYCERIDES

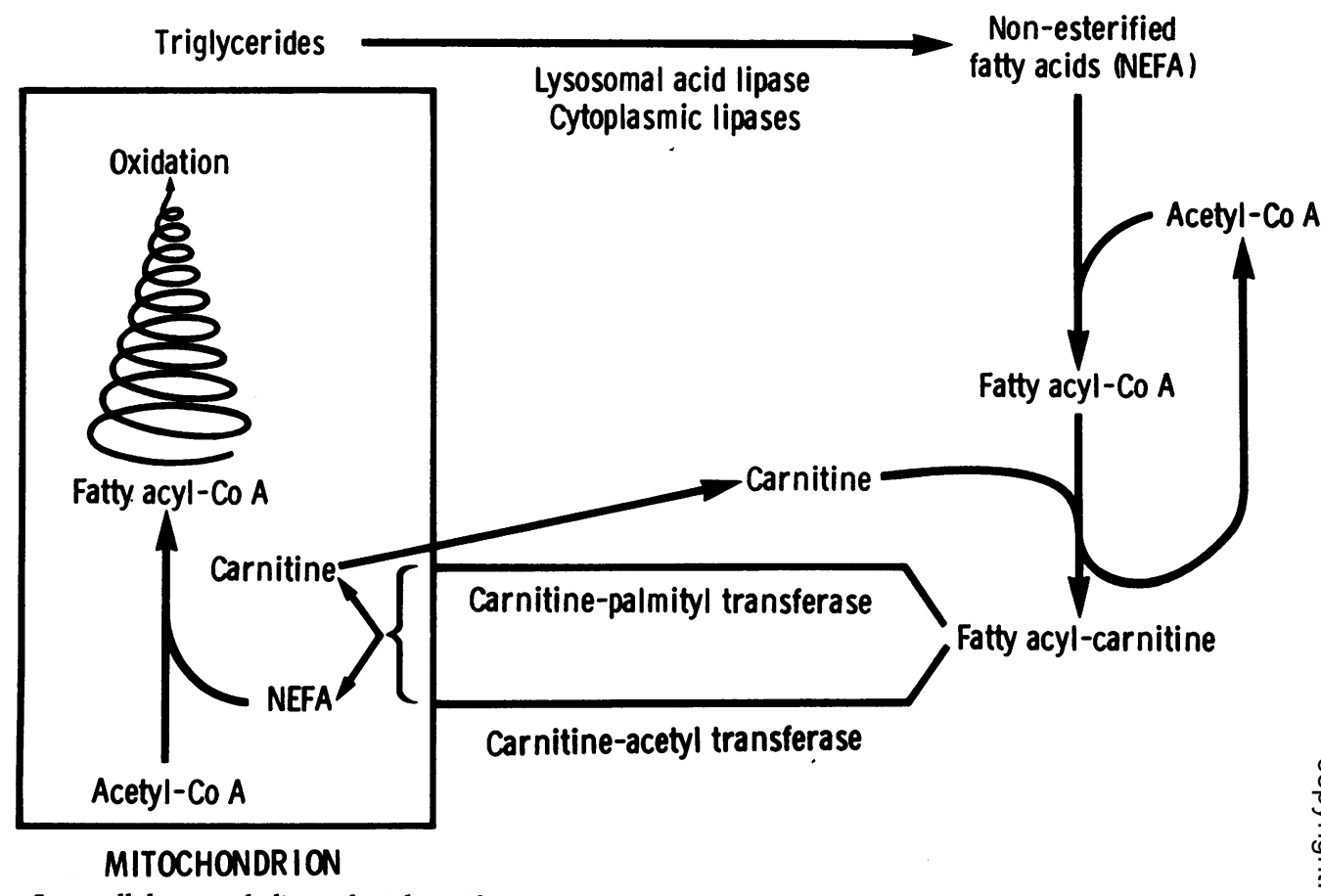

Fig 13 Intracellular metabolism of triglycerides

\section{Discussion}

Excess intracellular accumulation of triglycerides is a common finding in organs subject to metabolic insult. By contrast, inborn errors of metabolism characterized by neutral lipid deposition are rare (Sloan and Fredrickson, 1972) though local lipid excess has been reported with various clinical syndromes. Lipid vacuolation of white cells occurs in association with muscle disease (Jordans, 1953; Markesbery et al, 1974), and similar vacuolation of white cells was seen in two sisters with ichthyosis (Rosenazajn et al, 1966). Myopathy has been described with marked lipid deposition in muscle (Bradley et al, 1972; Engel et al, 1970; Engel and Siekert, 1972). The present case is of interest because each of these features is seen in a single patient, and in addition there is triglyceride deposition in cells of many types.

The association of ichthyosis with a defect of triglyceride metabolism is noteworthy because lipids play an important rôle in normal keratinization. Abnormal accumulations of crystalline phospholipids and cholesterol have been described in the keratin layer of ichthyotic skin (Nicolaides, 1964). $\overrightarrow{\vec{\rho}}$ The excess lipid deposition in the keratin layers of 3 this patient may merely reflect an hyperkeratosis but $?$ the lipid in the basal cells of the skin is abnormal.

The lesions are not typical of other generalized neutral lipid storage diseases. There is no significant storage of cholesterol or its esters as in cholesteryl $\frac{\sigma}{3}$ ester storage disease and cerebrotendinous xantho-matosis, and the serum bile acids are within normal limits (Sloan and Fredrickson, 1972). Wolman's disease, an inherited defect of lysosomal enzymes 은 usually fatal in infancy, may be characterized by $\frac{7}{0}$ deposition of triglyceride as well as cholesterol. An incomplete form of Wolman's disease might account $N$ for the features seen but the normal leucocyte acid lipase activity makes this unlikely. Moreover, in 0 Wolman's disease the excess lipid is stored in the $\omega$ lysosomes (Sloan and Fredrickson, 1972) but in this patient the excess triglyceride is free in cytoplasm unassociated with any organelles.

Histological examination of the jejunal mucosa $\stackrel{\mathscr{\rho}}{+}$ shows vacuolation of the columnar absorptive cells $\frac{7}{\circ}$ and resembles a-betalipoproteinaemia. In contrast $\stackrel{\circ}{\circ}$ there is also vacuolation of Paneth cells and of cells $\stackrel{\odot}{\Phi}$ 
in the lamina propria together with the widespread nature of the lesion in many organs. The fasting serum lipoproteins in this patient are quantitatively within the normal range but there is a relative excess of triglyceride in the betalipoprotein fraction with an abnormal triglyceride:cholesterol ratio. There is also a marked increase in the B-peptide of the apoprotein fraction. No clinical stigmata associated with lipoprotein anomalies are seen, and it is unlikely that these lipoprotein changes play a primary rôle in the genesis of the tissue lesions. The defect appears to be an intrinsic feature since cultured skin fibroblasts still show abnormal lipid accumulations when subcultured in medium containing normal lipoproteins.

Striated muscle fibres normally contain some cytoplasmic lipid droplets (Prineus and $\mathrm{Ng}$, 1967) which probably represent an energy store for the fibres. Non-specific lipid increase is often found in degenerating fibres (Reznik and Hansen, 1969) and is seen in a variety of diseases (Harriman and Reed, 1970). Lipid accumulation has been reported in association with severe myopathy (Bradley et al, 1972; Engel et al, 1970; Engel and Siekert, 1972) but in none of these instances was there any evidence of a generalized defect of lipid metabolism producing lesions other than in striated muscles. Engel and Angelini (1973) and Markesbery et al (1974) described patients with a lipid myopathy in association with carnitine deficiency; in the latter case lipid vacuoles were noted in granulocytes and Schwann cells.

The precise nature of the biochemical deficit in the present patient has not yet been elucidated. The pathways of intracellular lipid metabolism are outlined (fig 13). Carnitine deficiency, leading to impaired transport of fatty acids into mitochondria, is an attractive concept in this patient because she is a vegetarian obtaining little or no carnitine from her diet; this is not supported by the presence of normal plasma carnitine levels nor by the lack of effect when L-carnitine is added to fibroblasts in vitro.

Lysosomal and cytoplasmic lipases and the fatty acyl-carnitine transfetase systems are important in the mobilization and transport of long and short chain fatty acids into mitochondria. Preliminary studies indicate that the biochemical lesion may involve either a defect of these activities or impairment of fatty acid oxidation by mitochondria leading to the lipid deposition.

Our thanks are due to Dr Barry Lewis for the chemical analysis of the $\beta$-lipoprotein anomalies, to Dr P. K. Tubbs for the plasma carnitine levels, and to Dr D. Patrick for the leucocyte acid lipase estimations. Mrs Ruth White kindly typed the manuscript.

\section{References}

Anderson, D. R. (1965). A method of preparing peripheral leucocytes for electron microscopy. J. Ultrastruct. Res., 13, 263-268.

Bradley, W. G., Jenkinson, M., Park, D. C., Hudgson, P., Gardner-Medwin, D., Pennington, R. J. T., and Walton, J. N. (1972). A myopathy associated with lipid storage. J. Neurol. Sci., 16, 137-154.

Chanarin, I., Patel, A., Slavin, G., Wills, E. J., Andrews, T. M., and Stewart, G. (1975). Neutral-lipid storage disease. Brit. med. J., 1, 553-555.

Chayen, J., Bitensky, L., Butcher, R., and Poulter, L. (1969). A Guide to Practical Histochemistry. Oliver and Boyd, Edinburgh.

Engel, A. G., and Angelini, C. (1973). Carnitine deficiency of human skeletal muscle with associated lipid storage myopathy. Science, 179, 899-902.

Engel, A. G., and Siekert, R. G. (1972). Lipid storage myopathy responsive to prednisone. Arch. Neurol. (Chic.), 27, 174-181.

Engel, W. K., Vick, N. A., Glueck, C. J., and Levy, R. I. (1970). A skeletal muscle disorder associated with intermittent symptoms and a possible defect of lipid metabolism New Engl. J. Med., 282, 697-704.

Harriman, D. G. F., and Reed, R. (1972). The incidence of lipid droplets in human skeletal musclc in neuromuscular disorders: a histochemical, electron microscopic and freeze-etch study. J. Path., 106, 1-24.

Hirsch, J. G., and Fedorko, M. E. (1968). Ultrastructure of human leukocytes after simultaneous fixation with glutaraldehyde and osmium tetroxide and 'postfixation' in uranyl acetate. J. Cell Biol., 38, 615-627.

Jordans, G. H. W. (1953). The familial occurrence of fat containing vacuoles in the leukocytes diagnosed in two brothers suffering from dystrophia musculorum progressivo. (ERB) Acta med. scand., 145, 6, 419-424.

Luft, J. H. (1961). Improvements in epoxy resin embedding methods. J. biophys. biochem. Cytol., 9, 409-414.

Markesbery, W. R., McQuillen, M. P., Procopis, P. G., Harrison, A. R., and Engel, A. G. (1974). Muscle carnitine deficiency. Arch. Neurol. (Chic.), 31, 320-324.

Millonig, G. (1961). Advantages of a phosphate buffer for $\mathrm{OsO}_{4}$ solutions in fixation (Abstract). J. appl. Phys., 32, 1637.

Nicolaides, N. (1964). Lipids, membranes, and the human epidermis. In The Epidermis, edited by W. Montagne and W. C. Lobitz, Jr., pp. 511-538. Academic Press, New York and London.

Padykula, H. A. and Herman, E. (1955). The specificity of the histochemical method for adenosine triphosphatase. J. Histochem. Cytochem., 3, 170-195.

Prineus, J., and Ng, R. C. Y. (1967). Ultrastructural features of intracellular lipid in normal muscle. Neurology (Minneap.), 17, 1092-1098.

Reynolds, E. S. (1963). The use of lead citrate at high pH as an electron-opaque stain in electron microscopy. J. Cell Biol., 17, 208-212.

Reznik, M. and Hansen, J. L. (1969). Mitochondria in degenerating and regenerating skeletal muscle. Arch. Path., 87, 601-608.

Rosenazajn, L., Klajman, A., Yaffe, D., and Efrati, P. (1966). Jordans' anomaly in white blood cells. Blood, 28, 2, 258-265.

Sabatini, D. D., Bensch, K., and Barrnett, R. J. (1963). Cytochemistry and electron microscopy. The preservation 
of cellular ultrastructure and enzymatic activity by aldehyde fixation. J. Cell Biol., 17, 19-58.

Sloan, H. R., and Fredrickson, D. S. (1972). Rare familial diseases with neutral lipid storage. In The Metabolic Basis of Inherited Disease, edited by J. B. Stanbury, J. B.
Wyngaarden, and D. S. Fredrickson, 3rd edition, pp. $\frac{\stackrel{0}{\overrightarrow{0}}}{\frac{9}{6}}$ 808-832. McGraw-Hill, New York.

Watson, M. L. (1958). Staining of tissue sections for electron $\stackrel{\Rightarrow}{\Rightarrow}$ microscopy with heavy metals. J. biophys. biochem. Cytol., 4, 475-478. 